\title{
Orientation of Buildings: Predictive Control Based on the Calculation of Temperature and Solar Direct Contribution
}

\author{
${ }^{1}$ M. Hamdani, ' $S$. M. A. Bekkouche, ${ }^{1}$ M. K. Cherier, ' $N$. Benamrane, \\ ${ }^{2} \mathrm{~T}$. Benouaz \\ ${ }^{1}$ Unité de Recherche Appliquée en Energies Renouvelables, URAER, Centre de Développement \\ des Energies Renouvelables, CDER, 47133, Ghardaïa, Algeria \\ ${ }^{2}$ Laboratory of Electronic Physics and Modeling, University Abou Bakr Belkaïd \\ Tlemcen, Algeria \\ E-mail address: Hamdanimaamar@yahoo.fr
}

Keywords: Orientation; Temperatures; Building Materials;Multi Zone Area;

\begin{abstract}
The objective of this study was to use simulation as a tool to establish a possible relationship between orientation and energy performance of conventional residential buildings in Ghardaia. The findings of this study, when integrated in our site, will help in the realisation of efficient and sustainable energy performance of our built environment.
\end{abstract}

To illustrate the impact of the guidance on indoor air temperatures and solar gain of habitat has been studied for this type of climate (semi-arid).Along with this simulation using a TRNSYS (version16.1) was performed to validate the results of the field and to test several possibilities for guidance and improvements to determine the elements that can be used to better conditions.

From these results, it appears that the north and south directions during this period are more favorable with a small advantage for the south orientation. This is explained by the amounts of daily radiation incident on the two facades that are not significantly different $[1,2]$.

\section{INTRODUCTION}

The orientation of the building is a very important factor that is directly linked to standards for thermal comfort in the building. It is guided by natural elements like the sun and its intensity, wind direction, the seasons and temperature variations. The orientation of the building plays an important role in shading and daylighting levels. At first, the ideal specific heat of the material of the building envelope for the internal thermal mass is analyzed for buildings located in the region of Ghardaia (Algeria) specific desert climate environment, characterized by high radiation and temperature.

We will study the influence of the orientation of the building envelope on the temperature of the indoor environment for the different building materials (stone, hollow brick ...). By varying each time the orientation of the building by $90^{\circ}$ to the east or west, we are interested in determining the temperature of the inside air.

The structural materials should give the walls a good insulation and heat storage to mitigate the external temperature variations during the day grades: is inertia. The heat stored during the day by the walls is restored overnight. This characteristic is defined by the time of transfer. More thereof, the greater the inertia is large.

Good orientation can benefit from solar gain and reduce your heating bill [3, 5]. The orientation of a building meets several criteria: the need for natural light, the advantage of using solar radiation for heating, or rather the need to protect to prevent overheating, wind protection winter or benefit for summer refreshment are all important parameters for the choice of 
orientation. Also, the compact form, the reduction of the exchange surface with climate variability reduces sutured exposed to the external environment.

\section{PLAN DESCRIPTION}

In Ghardaïa region, stones are the most used as construction materials. It is has been used for centuries due to their availability and also due the lack of other construction materials. A typical most commonly used construction in the region had been chosen [5,9]. The figure 1 is a schematic of real apartment building situated at the first floor of two storey building. This building includes the following elements:

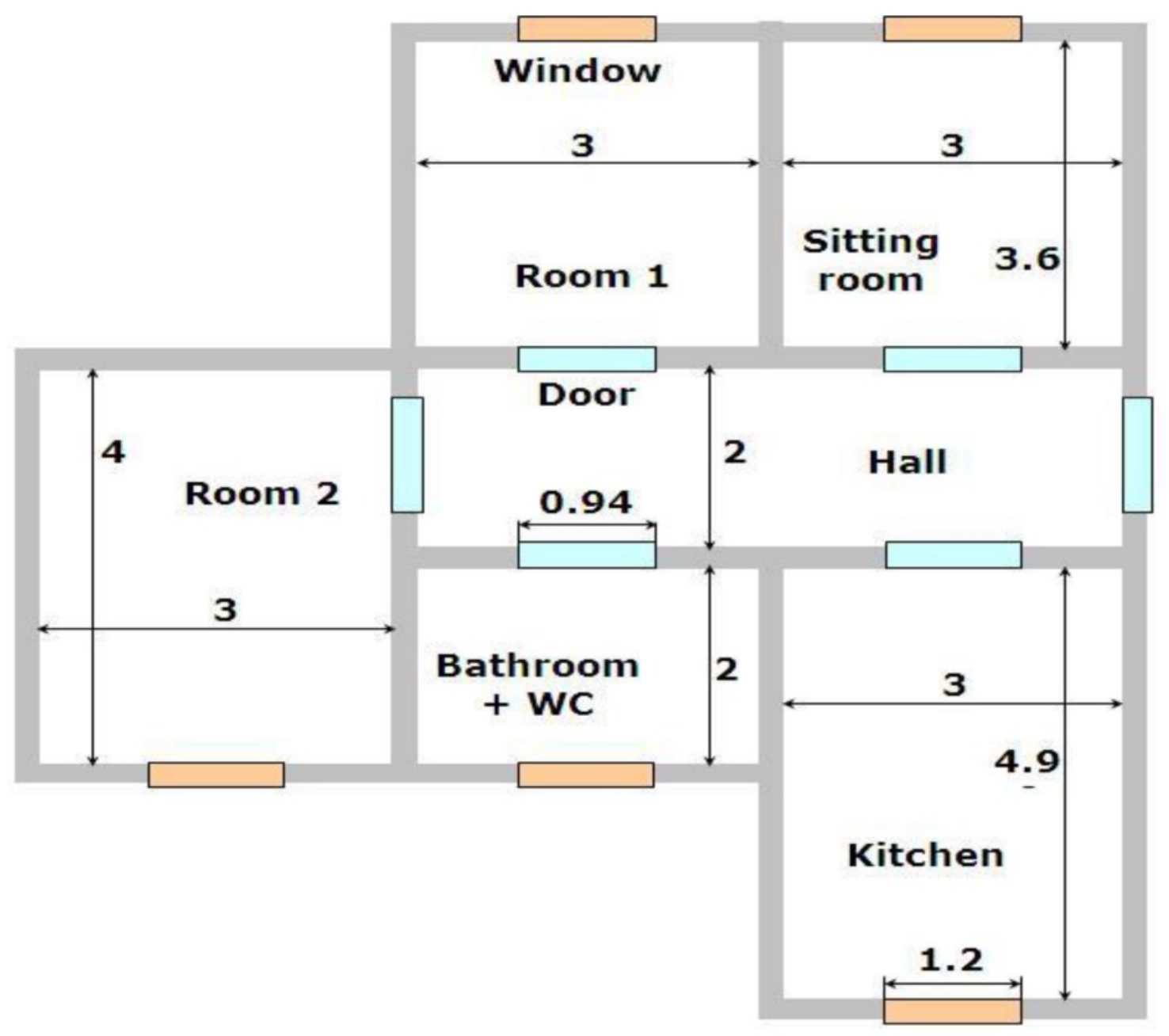

Figure 1. Plan descriptive pieces studie

\section{A. Thermo-physical properties walls}

In Ghardaiia region building envelops or outer wall consisting of a heavy structure generally constituted of stones $(40 \mathrm{~cm}$ thick), jointed and surrounded by two layers having thickness of $1.5 \mathrm{~cm}$ of mortar cement. The most inner face is coated with $1 \mathrm{~cm}$ thick plaster layer. The inner walls (or splitting walls) whose sides are in contact only with the internal ambient are considered to be of heavy structure constructed of stones of $15 \mathrm{~cm}$ width jointed and surrounded by two mortar cement layer of $1.5 \mathrm{~cm}$ thick and two layers of $1 \mathrm{~cm}$ thick of plaster (table 1).

We assume that the thermo physical characteristics of opaque walls are the same for all climates as shown in the following table 1: 
TABLE I. CARACTÉRISTIQUES THERMO-PHYSIQUES DES PAROIS OPAQUES.

\begin{tabular}{|l|l|l|l|l|l|}
\hline \multirow{5}{*}{ Exterior walls } & $\begin{array}{l}\text { Material and } \\
\text { wall } \\
\text { composition }\end{array}$ & $\begin{array}{l}\mathrm{L} \\
\mathrm{m}\end{array}$ & $\begin{array}{l}\lambda \\
\mathrm{Wm}- \\
1 \mathrm{~K}-1\end{array}$ & $\begin{array}{l}\rho \\
\mathrm{kg} \mathrm{m}-3\end{array}$ & $\begin{array}{l}\mathrm{cp} \\
\mathrm{J} \mathrm{kg}-1 \\
\mathrm{~K}-1\end{array}$ \\
& Mortar cement & 0.015 & 1.4 & 1800 & 1000 \\
\cline { 2 - 6 } & Stone & 0.4 & 2.3 & 2000 & 1000 \\
\cline { 2 - 6 } & Mortar cement & 0.015 & 1.4 & 1800 & 1000 \\
\cline { 2 - 6 } & Plaster & 0.01 & 0.56 & 1400 & 1000 \\
\hline Interior walls & Mortar cement & 0.015 & 1.4 & 1800 & 1000 \\
\cline { 2 - 6 } & Plaster clay & 0.01 & 0.45 & 1200 & 840 \\
\cline { 2 - 6 } & Stone & 0.15 & 2.3 & 2000 & 1000 \\
\cline { 2 - 6 } & Plaster clay & 0.01 & 0.45 & 1200 & 840 \\
\cline { 2 - 6 } & Mortar cement & 0.015 & 1.4 & 1800 & 1000 \\
\hline \multirow{5}{*}{ Ground } & Tiling & 0.025 & 6.14 & 2300 & 875 \\
\cline { 2 - 6 } & Cement & 0.02 & 1.4 & 1800 & 1000 \\
\cline { 2 - 6 } & Concrete dense & 0.2 & 2.4 & 2400 & 800 \\
\hline \multirow{3}{*}{ Roof } & Plaster & 0.015 & 0.56 & 1400 & 1000 \\
\cline { 2 - 6 } & $\begin{array}{l}\text { Lightweight } \\
\text { concrete }\end{array}$ & 0.12 & 0.33 & 800 & 719 \\
\cline { 2 - 6 } & Mortar cement & 0.015 & 1.4 & 1800 & 1000 \\
\hline & & & & & \\
\hline
\end{tabular}

The flooring is placed on plan ground; the concrete of the flooring is directly poured on the ground thus minimizing losses. Floor tiles are inter-imposed, it is an end coating resisting to corrosion and chemical agents. The roof is composed of cement slabs and concrete slab made so that it handles the load and be economical. A roof sloping of $5^{\circ}$ allowed water evacuation through several openings. Until now the flat roofs are considered as nest infiltration and as architectural solution.

\section{CONTROL OF SOLAR GAIN}

A direct gain system includes facing windows and a large mass placed within the space to receive the most direct sunlight in cold weather and the least direct sunlight in hot weather. In this type of system, sunlight passes through the windows, and its heat is trapped by the thermal mass in the room. In this situation we will require to change the orientation of the building to determine the direction that reduces the need to use heating and cooling systems by minimizing direct solar gain in summer and maximizing direct solar gain in winter. They are calculated by the following equation $[8,9]$ : 
$\mathrm{Q}_{\mathrm{s}}=24 \sum \mathrm{I}_{\mathrm{sj}} \mathrm{S}_{\mathrm{sj}}$

$\mathrm{S}_{\mathrm{sj}}=$ A S Fs

Surface openings, South side $A=3.36 \mathrm{~m} 2$.

Surface openings, North side A=3.36 m2.

Surface openings, East side $A=2.068 \mathrm{~m} 2$.

Surface openings, West side $A=2.508 \mathrm{~m} 2$.

$\mathrm{S}$ is the solar factor; is the ratio of the total solar energy

flux

entering the premises through the glass to the incident solar energy flux. For the carpentry wood

$\mathrm{S}=0.44$, it is all just the contribution of a Window to the heating of the room.

Fs is the correction factor for shading: for

North Fs $=0.89$

South Fs $=0.72$

East $\quad$ Fs $=0.67$

West $\quad$ Fs $=0.67$

Then we deduce Ssj:

$$
\begin{aligned}
& \text { Ss_South }=3.36 \times 0.44 \times 0.72=1.0644 \mathrm{~m}^{2} \\
& \text { Ss_North }=3.36 \times 0.44 \times 0.89=1.3158 \mathrm{~m}^{2} \\
& \text { Ss_East }=2.068 \times 0.44 \times 0.67=0.6096 \mathrm{~m}^{2} \\
& \text { Ss_West }=2.5080 \times 0.44 \times 0.67=0.7394 \mathrm{~m}^{2}
\end{aligned}
$$

So we can write:

$$
\begin{aligned}
& Q_{s}=I_{s_{-} \text {South }} S_{s_{-} \text {South }}+I_{s_{-} \text {North }} S_{s_{-} \text {North }} \\
& +I_{s_{-} \text {East }} S_{s_{-} \text {East }}+I_{s_{-} \text {West }} S_{s_{-} \text {West }}
\end{aligned}
$$

Is is the daily irradiation incident on the considered direction $(\mathrm{Wh} / \mathrm{m} 2)$.

The following table gives the average values of daily irradiation calculated for each month and for the four possible orientations (Table 1) [5, 9].

The obtained Fig. 2 presents the variation of the average daily solar gain calculated by Eq. (3) according to the four classical orientations: South, North, East and West. In the fifth curve (black color), we illustrate the average daily solar gain of the habitat oriented in full South but with considering that there are not openings in the Northern facade. 
TABLE II. MONTHLY AVERAGE DAILY IRRADIATIONS, GHARDAIA. $(\mathrm{WH} / \mathrm{M} 2)$

\begin{tabular}{|l|l|l|l|}
\hline & \multicolumn{1}{|c|}{ South } & \multicolumn{1}{c|}{ North } & \multicolumn{1}{c|}{ East and West } \\
\hline January & 6993 & 237 & 2665 \\
\hline February & 6863 & 283 & 3358 \\
\hline March & 5761 & 354 & 3892 \\
\hline April & 4155 & 661 & 4381 \\
\hline May & 2872 & 1400 & 4449 \\
\hline June & 2307 & 2035 & 4456 \\
\hline July & 2502 & 1721 & 4314 \\
\hline August & 3386 & 938 & 4106 \\
\hline September & 4712 & 489 & 3757 \\
\hline October & 5931 & 366 & 3256 \\
\hline November & 6583 & 283 & 2744 \\
\hline December & 6726 & 235 & 2351 \\
\hline
\end{tabular}

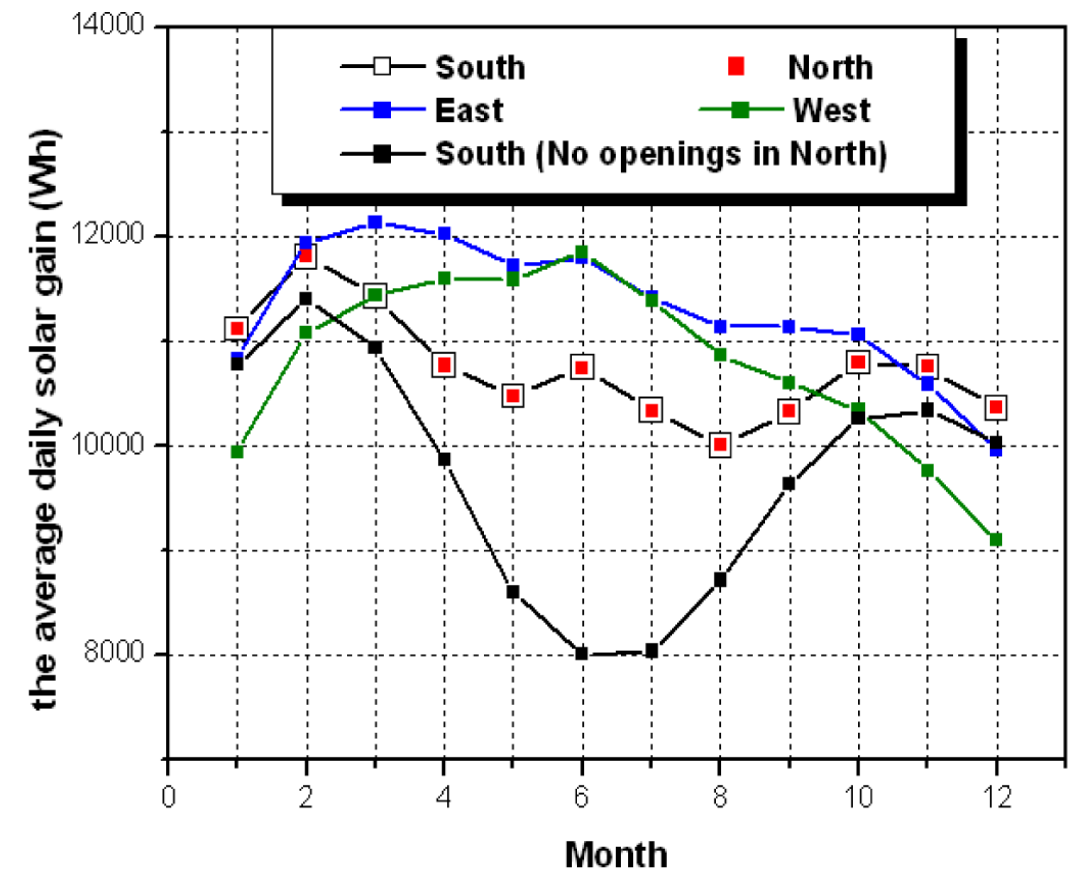

Figure 2. Average daily solar gain for each month, Ghardaïa

Calculations showed that to protect itself from the summer overheating caused by the solar gain, it is recommended to choose the Southern orientation between Mars and September and the Western orientation for October. On the other hand, to benefit from this solar gain, it is preferably to choose the Eastern orientation for February and Southern orientation between November and January. However, we can say that the prevailing orientation is South. Even if we refer to February and October remarks, we can see that the difference in solar gain is not considerable compared to the Southern orientation. We can also draw from this study that closing openings of North facade reduces the solar gain in hot weather. 
Consequently, this initial study shows that to effect significant energy savings, specialist forms of shading are needed, combining low solar transmittance in summer with useful solar gain in winter. These situations lead us to think about the integration of eaves. In winter the angle between the rays and the horizontal is less important in summer many winter rays pass under the eaves and reach the facade. While some summer rays reach the facade; they are stopped by eaves.

\section{MODELING AND SIMULATION}

For validation of the results of indoor thermal comfort was made use of: Thermal Dynamics Simulation by TRNSYS software (version 16.1) using the Type 56b. The simulation is limited to quantify the ambient temperature, humidity and checks the internal and external surface temperatures of the tested areas. The key parameter in the simulations is the coefficient of heat transfer equivalent to be determined for each material. The idea is to have a first comparison of the air temperature of each area and to properly identify the directions of heat transfer. This study allows us to describe the evolution of the internal temperatures of the building as a summer or winter. The initial conditions of all surfaces and air were chosen from the experimental values [4].

Data processing is performed on selected measures covering the year 2013 collected every ten minutes for the site of Ghardaia. All these steps will choose reliable and adequate models that can be exploited in these studies concerning the effect of the orientation of such a dwelling on its internal temperatures.

\section{RESULTS AND ANALYSIS}

The thermal behavior of the building is very complex because of the heat transfer occurring simultaneously and the variation of conditions seeking (climatic conditions). TRNSYS integrates these phenomena in the transient thermal modeling of the building as follows: heat transfer within the envelope are processed using TRNSYS Type56. Knowing that a building wall may give rise to three different heat transfer, the simulation is limited to quantify the ambient temperature, humidity and check internal and external surface temperatures tested areas. The key parameter in the simulations is the coefficient of heat transfer equivalent to be determined for each material. This study allows us to describe the evolution of the internal temperatures of the building seen in the summer as a guide. Based on climatic data from a weather station located at our unit. Data processing is performed on selected measures covering the year 2013 collected every ten minutes for the site of Ghardaia. These data are necessary for the definition of all possible orientations for the exterior walls and windows. For each orientation agreed, an input of incident radiation to the component type name TRNSYS 56 will be necessary . This is usually provided by the Type109. At first it was necessary to introduce weather data for the town of Ghardaia contained in the library of TRNSYS type 109 by user and vary each time the orientation of the building by 90 degrees to the east or the West, it helps to make the South West Wall, the Western Wall in the North, North East wall and the east wall becomes South.

The days of 19 to 24 July 2013 were selected to perform the numerical simulation gives the influence of the orientation of the habitat on its internal temperatures. Figure (3) also describes the daily changes of the temperature inside the room for the other three rotations air: eastward, westward and northward

Figure 4 provides a graphical interface that corresponds to climate site data Ghardaia 19-24 July 2013. The blue curve represents the relative humidity, the green curve is the ambient temperature, the brown is relative to the incident solar power and purple curve describes the behavior of the instantaneous wind speed. Figure 4 shows the temperature profiles of the air from the living room to the guidelines previously cited during these days. 
From these results, it appears that the north and south directions during this period are more favorable with a small advantage for the south orientation. This is explained by the amounts of daily radiation incident on the two facades that are not significantly different.

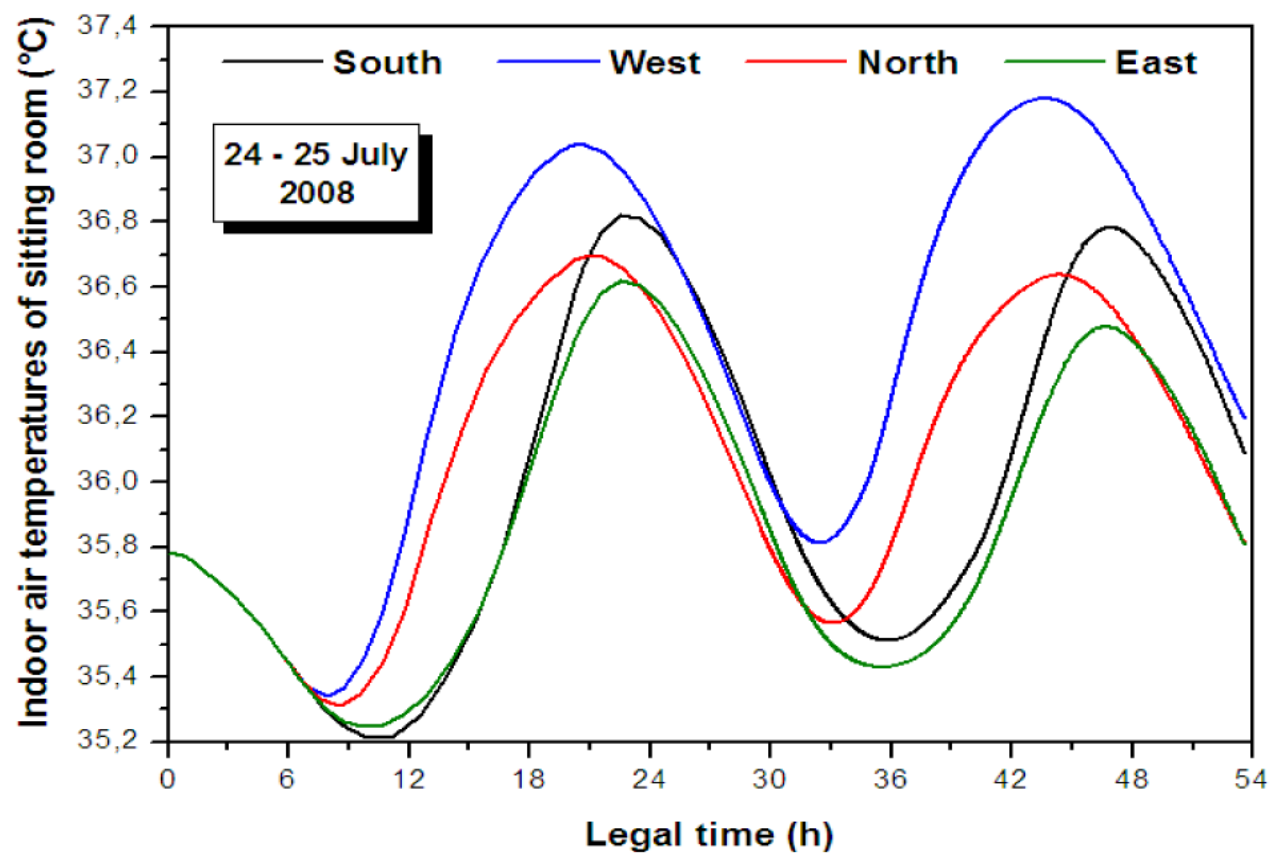

Figure 3. . Sitting room temperatures, July 24 and 25, 2008.

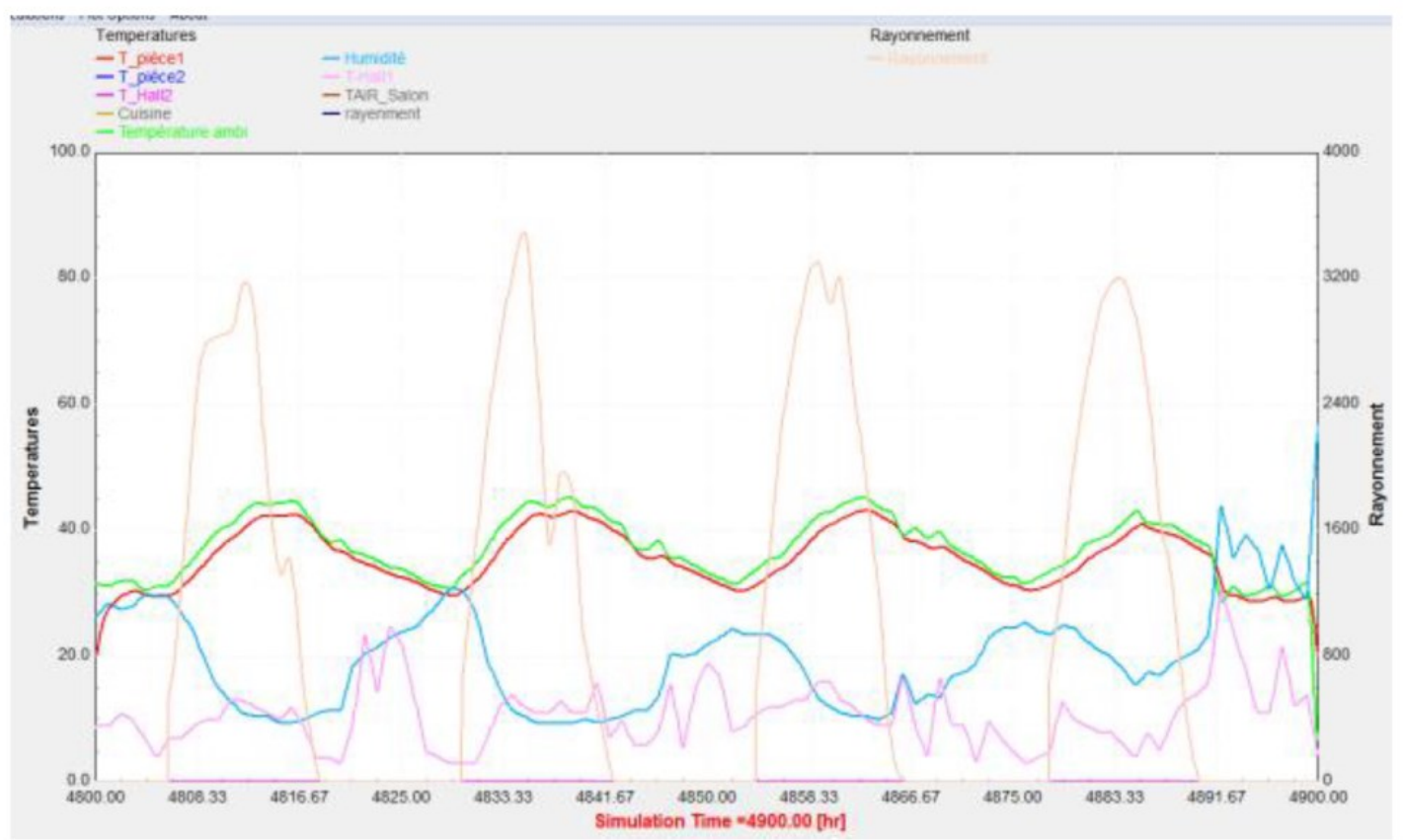

Figure 4. solar radiation and climate data at the site of Ghardaia, July 19 to 24, 2013. 


\section{CONCLUSION}

As a conclusion, the calculations show that under real meteorological conditions, the time lags and decrement factors of walls change their values depending on the variations of the outdoor temperature, wind velocity, solar radiation and the building's orientation. A sufficient time lag and a low decrement factor will delay the hot outdoor temperature which will comes at the end of the day in the building, period in which it is more easy to cool off with a single opening windows.

Simulated temperatures prove that the optimal building orientation depends largely on the building materials, thermal inertia, compactness index and the contact mode with the outside.

TRNSYS calculation tool has allowed us to validate our model, integrating climate data site (METEONORM] for a home built with local materials and according to current standards.

\section{References}

[1] Moummi, Estimation du Rayonnement Solaire par deux Approches Semi-empiriques dans le Site de Biskra .8ème Séminaire International sur la Physique Energétique, Centre Universitaire de Bechar, Algérie, 11 et 12 Novembre 2006.

[2] D.Medjelekh, Impact de L'inertie Thermique sur le Confort Hygrothermique et la Consommation Energetique du Batiment. Memoire de Magister en Architecture Bioclimatique, Université Mentouri de Constantine, 2006M.

[3] Wegmuller, J. P. von der Weid, P. Oberson, and N. Gisin, High resolution fiber distributed measurements with coherent OFDR.in Proc. ECOC'00, 2000, paper 11.3.4, p. 109.

[4] F. Ali-Toudert, H. Mayer, Numerical study on the effects of aspect ratio and solar orientation on outdoor thermal comfort in hot and dry climate.Building and environment.

[5] M. Hamdani, S.M.A. Bekkouche, T. Benouaz, M.K. Cherier, Choix d'un Modèle Numérique Adéquat pour 1'Estimation des Eclairements Incidents à Ghardaïa. Premier Séminaire International sur les Energies Nouvelles et Renouvelables, Ghardaïa, 11-12 Octobre 2010.

[6] M. Hamdani, S.M.A. Bekkouche, T. Benouaz, M.K. Cherier, N. Benamrane et O.Halloufi , Effect of Orientation of Buildings With Different Materials in Distribution of Temperatures in Walls Thickness . 13th International Multidisciplinary Scientific GeoConference SGEM 2013, June 16-22, 2013, 91 - 98 pp, Albena, Bulgaria. SGEM Scientific Papers DataBase -Renewable Energy Sources and Clean Technologies. DOI:10.5593/SGEM2013/BD4/S17.012

[7] P. Rumianowski, J. Brau, et J.J Roux, An Adapted Model for Simulation of the Interaction Between a Wall and the Building Heating System. In Proceedings of the Thermal Performance of the Exterior Envelopes of Buildings IV Conference Orlando, USA, p. 224-233, 1989

[8] S.M.A Bekkouche, T. Benouaz, M.K. Cherier, M. Hamdani et M.R Yaich, choix des Matériaux de Construction d'un Habitat, Considérations Thermiques et Environnementales. premier Séminaire International sur les Energies Nouvelles et Renouvelables, Ghardaïa, 1112 Octobre 2010.

[9] S. M. A. Bekkouche, T. Benouaz, M. K. Cherier, M. Hamdani, M. R. Yaiche et N Benamrane, Influence of the compactness index to increase the internal temperature of a building in saharan climate, Elsevier, Energy and Buildings vol. 66 (2013) pp. 678-687. 